\title{
Global renewable energies: a dynamic study of implementation time, greenhouse gas emissions and financial needs
}

Received: 18 January 2005/ Accepted: 10 May 2005/Published online: 25 November 2005

(C) Springer Verlag 2005

\begin{abstract}
The current worldwide energy consumption is largely dominated by non-renewable energies such as coal, oil and gas. For well-known reasons, this concept should be changed to a more sustainable one based on renewables. As learned from history, a transition from one energy system to another has always taken about 100 years. A dynamic material flow model is developed to simulate some key elements for the implementation of renewable energy systems on a large scale. These key elements are the required industrial capacity, the energy and financial requirements and the impact on greenhouse gas mitigation. Results are presented for wind, photovoltaic, hydro, solar thermal, geothermal and biomass electrical energy systems. The comparison of two different implementation strategies, moderate $\approx 60$ years and fast $\approx 30$ years, shows that the implementation time is the only limitation, resulting in large production overcapacities. The energy and financial needs are not as critical. The implementation of renewables on a large scale would considerably reduce $\mathrm{CO}_{2}$ emissions by 2 tons per person per year for a world population of 7 billion people.
\end{abstract}

Abbreviations kWh: Kilowatt hour - MW: Megawatt MWh: Megawatt hour $\cdot$ Y: Year $\cdot$ J: Joule

\section{Introduction}

Availability of energy is a key element to achieve the interrelated economic, social and environmental goals of sustainable development of modern human society.

H. P. Bader $(\bowtie) \cdot$ R. Scheidegger

EAWAG, Überlandstr. 133, 8600 Dubendorf, Switzerland

Email: bader@eawag.ch

Tel: +4118235501

Fax: + 4118235398

M. Real

Alpha Real AG, Feldeggstr. 89, 8008 Zurich, Switzerland
However, today about $86 \%$ of the total energy consumption is based on non-renewable forms of energies (WEC 2000; OECD/IEA 2004). Indeed the use of fossil fuels account for $320 \times 10^{18} \mathrm{~J}$ of primary energy, nuclear $26 \times 10^{18} \mathrm{~J}$ and renewable $56 \times 10^{18} \mathrm{~J}$ (WEC 2000). Since the rebuilding rate of fossil energy reserves is approximately $10^{6}$ times slower than the present rate of tapping, today's use of fossil energies is far from being sustainable. Furthermore, emissions of anthropogenic greenhouse gases, mostly from the production and use of these non-renewable energies, are altering the atmosphere in ways that may already be having a discernible influence on global climate. In the IPCC ${ }^{1}$ third assessment report, "Climate Change 2001", conclusions were drawn that "there is new and stronger evidence that most of the warming observed over the last 50 years is attributed to human activities".

In addition, dependence on imported fuels leaves many countries vulnerable to disruption of supply. Two billion people (Bader et al. 2003) have no access to these forms of today's established flows of electrical energies. This certainly runs counter to the concept of human development and presents a constant threat to social stability.

The agreement on the Kyoto protocol reached in Marrakech on November 2001 is certainly a major step towards reducing greenhouse gas emissions. The consensus to reduce $\mathrm{CO}_{2}$ is international, with the major exception of the USA, which ironically is also the major contributor of emissions threatening global climate. However, even if this agreement is fundamental, it will not alter the energy supply paradigm essentially. It can be considered as a very important first step with realistic short-term goals measurable in the near future. As can be seen in the history, the change of an energy supply system such as from wood to coal and then, 100 years later, to oil fuel required each time about a century. The

\footnotetext{
${ }^{1}$ The Intergovernmental Panel on Climate Change (IPCC) was jointly established in 1988, by the World Meteorological Organi zation and the United Nations Environment Programme (UNEP).
} 
question then arises of course, how long will it take to alter today's non-sustainable energy supply system to a system based on renewables? If human society decides to leave the path of fossil based energy paradigm, how fast can renewables take over?

The United Nations framework convention on climate change (UNFCCC) has evaluated the role of technology transfer in addressing climate change in great depth (IPCC 2000). The conclusion is that it will require technological innovations and widespread transfer and implementation of technologies based on renewables and improved efficiency for mitigation of greenhouse gas emissions. The question then arises of whether the innovations can occur fast enough and continue over a period of time to allow greenhouse gas concentration to stabilize.

In the last three decades, many studies on renewables as well as on non-renewables have been carried out. The interested reader is referred to Real (1998), UNDP (2000), OECD/IEA (2004) and references therein. In many papers and reports the potential of renewable energy supply systems on a global scale has been estimated. Other studies addressed various technical aspects such as the technical feasibility, the energy efficiency and others. A third group of publications investigated environmental aspects and in particular the $\mathrm{CO}_{2}$ emissions related to construction and operation of energy supply systems. Finally, the resource consumptions as well as economic questions from the costs for construction, operation to the price of produced end energy have been analysed. Only few studies focused on the implementation of renewable energy systems on a large scale including possible limitations. Their main topic were trend extrapolations to estimate the future capacity of energy supply systems. However, as is well known (Hug et al. 2004 and references therein), such trend analysis are not able to discuss longer time periods of 50-100 years, which are characteristic for the transition between energy supply systems.

This study analyses the special challenge of potential industrial and economic constraints which may be induced by such a transfer from a fossil-based energy supply to an energy paradigm based purely on renewables:

1. How fast do industrial capacities have to grow to reach the target potential of renewable energy supply systems?

2. Which capital is required and which costs are induced by such a development?

3. What is the impact of such a development on greenhouse gas mitigation?

Within the study, results are presented for two different scenarios, simulating two different implementation patterns.

The development of major indicators over time has been simulated, to be used to identify potential bottlenecks in large-scale implementation. Such limitation can, for example, occur due to limited growth in industrial manufacturing capacity or excessive needs of trained installers or of capital.

Renewables in this context are energies which are based on the constant flow of energy from the sun or from the earth centre to the surface and include in its major forms solar, wind, biomass, hydro, oceanic and geothermal energies. Many of these forms of energy are not evenly distributed on the globe, neither are fossil fuels nor nuclear. The important question of the global, daily and seasonal variations is not dealt within this study. It is assumed that as time goes on, and the percentage of renewables increases, improved ways of storing and distributing energies will further develop. Hydrogen or ethanol from sugar-based biomass may play such an important role. These questions are important, but not within the goal of this study.

The method and results are exemplified by an analysis of wind, hydro, PV, solar thermal (solar collectors and solar thermal electricity), biomass (electricity only) and geothermal (electricity and heat) power generation.

Considered characteristics of these technologies include: world-wide potential, development of industrial capacity over time, growth rate and required time for implementation, specific energy requirements for manufacturing the systems, related yearly energy production and the potential to reduce greenhouse gas emissions.

\section{Method}

Much work has been performed on both the international and national level (Germany, Switzerland, USA and many other countries) to simulate various energy supply scenarios and possible impact on climate, biodiversity and human development. One of the most recent and probably most comprehensive evaluations was published by the IPCC report on climate change 2001, in which a future world was modelled in seven scenarios (IPCC 2001). Variations in assumptions include differences in growth pattern, population, technology mixes and variations in global solutions to economic, social and environmental sustainability.

Results of that very detailed analysis are often presented in graphical forms, sometimes also called "spaghetti graphs". This term reflects the fact that the huge variations in assumptions lead to a large variation in future development.

Within the method applied in this study, no such variations in potential, economic growth and populations have been simulated. The questions analysed are simply: What would be possible limitations if today's fossil fuel civilization would turn over to a renewable energy supply? And what would be the impact on $\mathrm{CO}_{2}$ mitigation, how fast and at what cost? The following possible limiting factors are considered: the implementation time, the (available) industrial capacities, the energy needed for manufacturing, the capital 
required and the resulting costs. Emphasis is given to modelling the evolution of indicators (see below) as a function of time, in order to understand the possible limitations, the size of the required effort and the time when such impacts would peak.

As analysed in depth by the World Energy Assessment initiated by UNDP, UNDESA and World Energy council in late 1998, the potentials of renewables are not a limiting factor per se for achieving a society with similar energy needs as today, based on renewables rather than on fossil energies. These potentials for renewables were adopted here and not revised.

The questions discussed here can simply be reduced to a key question: if global climate change would be considered seriously and a change in energy supply paradigm towards renewable near zero emissions technologies would be forced on a global scale, how fast and with what cost could such a transformation take place?

The method applied to answer the key question above is the dynamic material flow analysis. This method is described in detail in the literature (Baccini and Bader 1996). In the last decade it has been applied in numerous studies in different fields: Zeltner et al. (1999), Real (1998), Binder et al. (2001), Bader et al. (2003), Hug et al. (2004), Müller et al. (2004), Schmid et al. (2004) and ongoing work. The methodological procedure is as follows: (1) system analysis, (2) mathematical description including the formulation of the model approach, (3) calibration and (4) simulation including sensitivity and uncertainty analysis as well as parameter variation.

\section{System analysis}

In the system analysis, the system boundary and the relevant processes and the interactions (flows of material, energy, $\mathrm{CO}_{2}$ and money), have to be defined. By "relevant" we mean that the approximation level (processes and flows) should be chosen as simple as possible in order to address the questions asked. The geographical border is the "world", since we are interested in the worldwide implementation of renewable energy systems.

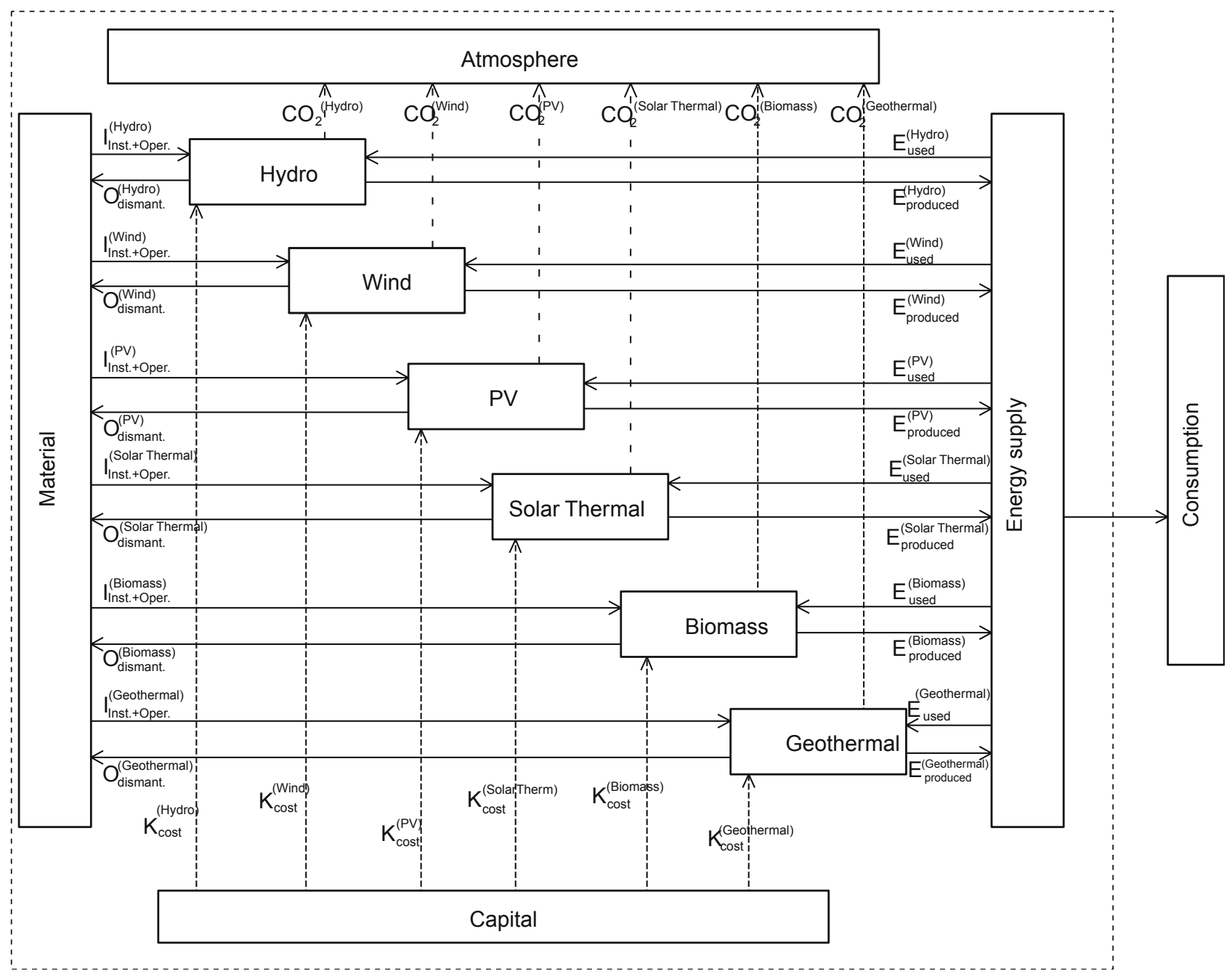

Fig. 1 System analysis for installation, dismantling and operation of renewable power plants 
To answer the key questions above it is necessary to gain an overview of the material, energy, induced $\mathrm{CO}_{2}$ and money flows, which are important for manufacturing and operating the renewable energy supply systems.

For reasons of simplicity we restrict in the following to electrical energy supply systems. Figure 1 shows a very simplified system to describe these renewable energy systems in a first approximation. Taken into account are hydro, wind, PV, solar thermal, biomass and geothermal electrical energy systems.

$I_{\text {inst + oper }}$ and $O_{\text {dismantling }}$ describe the production and dismantling capacity per year. $E_{\text {used }}$ and $E_{\text {produced }}$ represent the energy used for manufacturing, installation and operation and the produced energy per year, respectively. $K_{\text {cost }}$ and $\mathrm{CO}_{2}$ are the sums of all costs and $\mathrm{CO}_{2}$ equivalent emissions per year resulting from installation and operation.

Clearly the system of Fig. 1 is too simple to describe all material, energy, $\mathrm{CO}_{2}$ and money flows related to renewable energy systems. However, to gain a first insight into the characteristic behaviour of these flows, indicators are chosen. Indicators typically represent flows of a group of flows. In our case, the arrows in Fig. 1 are the indicators for the "material", "energy", " $\mathrm{CO}_{2}$ " and "financial" household induced by renewables.

\section{Mathematical model}

It is obvious that the system of Fig. 1 is built up by independent subsystems, each representing a specific type of power plant. Therefore each subsystem can be treated as mathematically independent. Since all subsystems are mathematically equivalent, the procedure is illustrated only for the subsystem wind.

The following variables describe the subsystem wind: The first three variables are the indicators for the material household of System analysis section. Variables 4-6 represent the energy household, variables 7-11 the financial household and variables $12-13$ the induced $\mathrm{CO}_{2}$ emissions. Note that for reasons of clarity, some of these variables are aggregated in Fig. 1. Of course, a complete description of all details of the subsystem wind, with its innumerable processes and materials involved, would require many more variables than shown in variable list (Eq. 1). However, to answer the key questions above, the variables (Eq. 1) are a minimal necessary set.

Note that description (Eq. 1) considers only the costs, resulting in the prime costs for producing the energy. The selling price, including also a profit, is not a subject of this study.

The system equations describe the system behaviour mathematically. Clearly the assumptions made in these equations should be as simple as possible, whereas the model should be as accurate as possible. The model approach here is a generalization of those used in Real (1998) and Hug et al. (2004) to include also the " $\mathrm{CO}_{2}$ " and "financial" household. For the subsystem wind, described by the variables (Eq. 1), the system equations, consisting of balance and "model-equations" are as follows:

\section{"Material" household}

1. Balance equation for number of wind-turbine units:

$\dot{M}(t)=I(t)-O(t)$,

$\dot{M}(t)$ is the derivative of $M(t)$ with respect to time.

2. Implementation of wind turbines:

$M(t)=P_{1}(t)$.

3. Dismantling of wind turbines:

$$
O(t)=\int_{0}^{t} k\left(t, t^{\prime}\right) I\left(t^{\prime}\right) \mathrm{d} t^{\prime}
$$

$M(t)$ number of installed operating wind-turbines units (MW) at time $t$,

$I(t)$ number of newly installed wind-turbines units per year,

$O(t)$ number of dismantled wind-turbine units per year,

$E_{\text {inst }}(t)$ energy used for manufacturing and installation of wind turbines per year,

$E_{\text {oper }}(t)$ energy used for operation (including maintenance) per year,

$E_{\text {prod }}(t)$ energy generated by the installed wind-turbine units per year,

$K_{\text {inst }}(t)$ costs of manufactured wind-turbine units per year,

$K_{\text {oper }}(t)$ costs for operation (incl. maintenance) per year,

$K_{\text {cap }}(t)$ capital (used to finance new installations),

$K_{\text {int }}(t)$ costs resulting from interest of the capital per year,

$K_{\text {back }}(t)$ costs of capital-repayment per year,

$C_{\text {inst }}(t)$ amount of emitted $\mathrm{CO}_{2}$ caused by new installations per year,

$C_{\text {oper }}(t)$ amount of emitted $\mathrm{CO}_{2}$ caused by operation per year. 
$P_{1}(t)$ is a parameter function describing the assumed implementation of wind turbines as a function of time. $k\left(t, t^{\prime}\right)$ is the transfer function or lifetime distribution of wind turbines installed at time $t^{\prime}$.

\section{"Energy" household}

4. Energy required for manufacturing and installation of wind turbines:

$E_{\text {inst }}(t)=P_{2}(t) \cdot I(t)$.

5. Energy required for operation of wind turbines:

$E_{\text {oper }}(t)=\int_{0}^{t} I_{\text {Rest }}\left(t, t^{\prime}\right) \cdot P_{3}\left(t^{\prime}\right) \mathrm{d} t^{\prime}$.

6. Generated energy by wind turbines:

$E_{\text {prod }}(t)=\int_{0}^{t} I_{\text {Rest }}\left(t, t^{\prime}\right) \cdot P_{4}\left(t^{\prime}\right) \mathrm{d} t^{\prime}$.

The three parameter functions $P_{2}(t), P_{3}(t)$ and $P_{4}(t)$ are the specific energy requirement for manufacturing, for operation and the specific energy generation per wind turbine unit per year, respectively. $I_{\text {Rest }}\left(t, t^{\prime}\right)$ is the number of new installations $I\left(t^{\prime}\right)$ at time $t^{\prime}$, which are still in operation at time $t$. Mathematically:

$I_{\text {Rest }}\left(t, t^{\prime}\right)=I\left(t^{\prime}\right)\left[1-\int_{t^{\prime}}^{t} k\left(t^{\prime \prime}, t^{\prime}\right) \mathrm{d} t^{\prime \prime}\right]$.

"Financial" household

7. Costs for manufacturing and installation of wind turbines:

$K_{\text {inst }}(t)=P_{5}(t) \cdot I(t)$.

8. Costs for operation of wind turbines:

$K_{\text {oper }}(t)=\int_{0}^{t} I_{\text {Rest }}\left(t, t^{\prime}\right) \cdot P_{6}\left(t^{\prime}\right) \mathrm{d} t^{\prime}$.

9. Capital used to finance new installations (balance equation):

$\dot{K}_{\text {cap }}(t)=K_{\text {inst }}(t)-K_{\text {back }}(t)$.

10. Cost of interest:

$K_{\text {int }}(t)=P_{7}(t) \cdot K_{\text {cap }}(t)$.

11. Capital repayment:

$K_{\text {back }}(t)=\int_{0}^{t} P_{8}\left(t, t^{\prime}\right) \cdot K_{\text {inst }}\left(t^{\prime}\right) \mathrm{d} t^{\prime}$.
The parameter functions $P_{5}(t)$ and $P_{6}(t)$ are the specific costs for manufacturing, installation and operation per wind-turbine unit per year. $P_{7}(t)$ is the interest as a function of time. $P_{8}\left(t, t^{\prime}\right)$ is the part of costs of manufacturing $K_{\text {inst }}\left(t^{\prime}\right)$ paid at time $t^{\prime}$ which is repaid at time $t$.

\section{Induced $\mathrm{CO}_{2}$-equivalent emissions}

12. $\mathrm{CO}_{2}$-equivalent emissions due to manufacturing and installation of wind turbines:

$C_{\text {inst }}(t)=P_{9}(t) E_{\text {inst }}(t)$.

13. $\mathrm{CO}_{2}$ emissions due to operation of wind turbines:

$C_{\text {oper }}(t)=P_{10}(t) E_{\text {oper }}(t)$.

The parameter functions $P_{9}(t)$ and $P_{10}(t)$ are the specific $\mathrm{CO}_{2}$ emissions per energy unit used for manufacturing and operation of wind turbines.

The 11 parameter functions $P_{1}(t), \ldots, P_{10}(t)$ and $k(t$, $\left.t^{\prime}\right)$ are the characteristic quantities describing the behaviour of the system considered. They can be divided into two different groups, representing two different kinds of system properties. The first group is the group of "technical functions" containing the lifetime distribution $k\left(t, t^{\prime}\right)$, and the specific quantities $P_{2}(t), P_{3}(t), P_{4}(t)$, $P_{9}(t)$ and $P_{10}(t)$. Each parameter function of this group represents the "state of the art" of technical progress. The second group includes the "stakeholder related functions", namely $P_{1}(t), P_{5}(t), P_{6}(t), P_{7}(t)$ and $P_{8}\left(t, t^{\prime}\right)$. They represent the political, socio-economic and economic intentions, originating from decisions of the stakeholders.

To show the interactions and assumptions made, Eqs. 2, 3, 4, 5, 6, 7, 8, 9, 10, 11, 12, 13, 14 are schematically illustrated for the subsystem wind in Fig. 2.

To describe the system of renewables of Fig. 1 completely, some "integral" variables have been added describing the total energy supply, total energy production, total costs, total capital etc.

This led to a system of 224 variables in total. The corresponding system equations form a system of 224 sparsely coupled integro-differential equations which can only be solved numerically. The equations contain 98 parameter functions, described by up to 269 single parameter values, which are defined by the calibration procedure below.

The initial conditions for the variables follow from the initial values of the parameter functions and the system equations for $t=0$.

The equations have been implemented in the computer simulation program SIMBOX. All calculations have been done on a Pentium IV PC.

Calibration

Calibration is the art of finding the most appropriate parameter functions to fit the available data. Obviously 


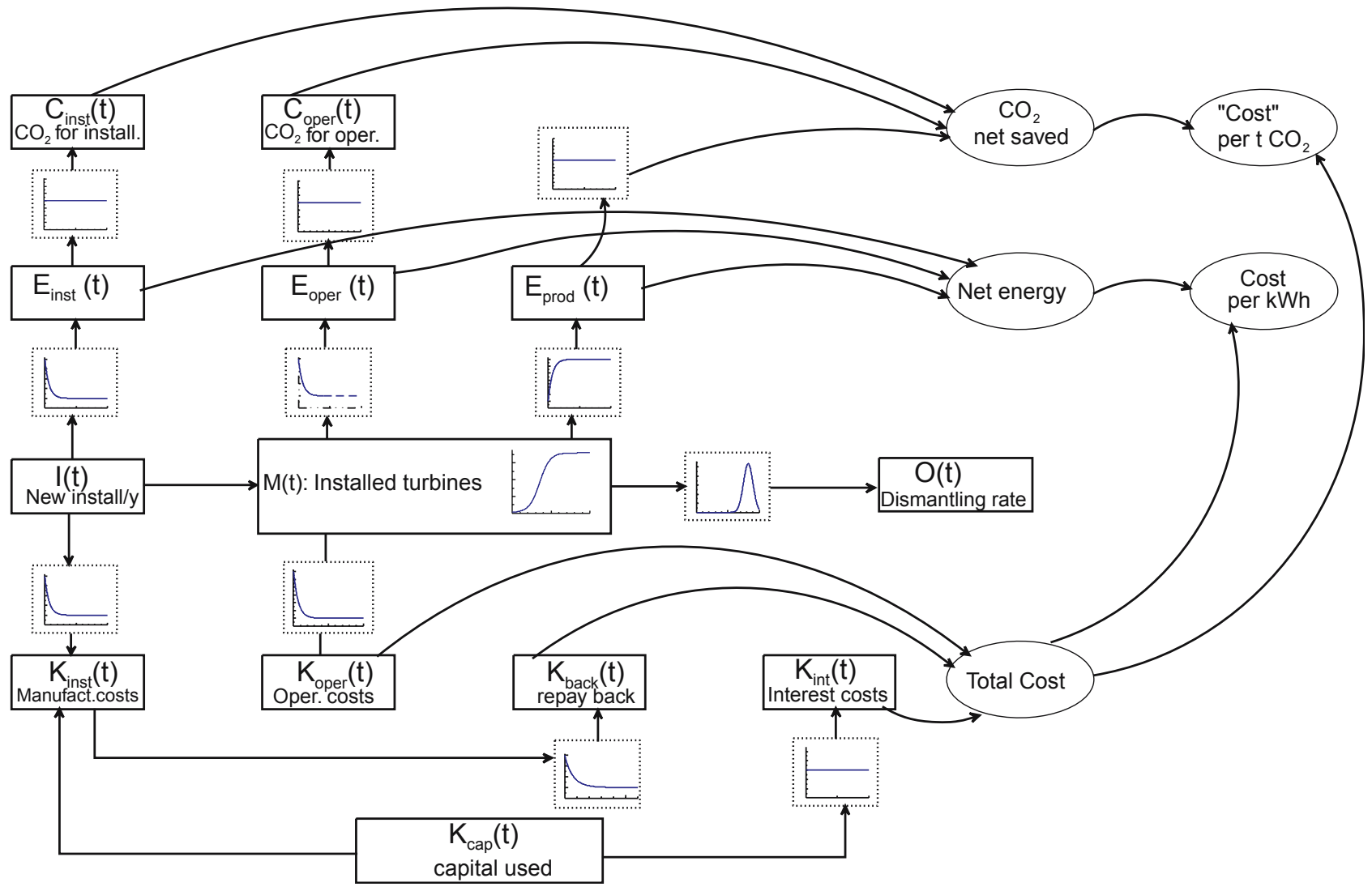

Fig. 2 The interactions and assumptions of Eqs. 2, 3, 4, 5, 6, 7, 8, $9,10,11,12,13,14$ schematically. The boxes with the solid lines represent the variables and the boxes with the dotted lines the parameter functions. The horizontal and vertical arrows indicate the

this is in general not uniquely possible and not independent of subjectivity of the investigator. However, the chosen parameter functions should be as simple as possible to guarantee a minimal set of necessary parameters. In this sense the following parameter functions were found to be most suitable.

\section{Data sources}

In order to perform the evaluation, a set of data has to be assumed concerning overall potential of the technologies for tapping the wind, solar, biomass hydro and geothermal sources, the growth rate of implementation, required capital and energy flows, greenhouse gas mitigating potential, cost issues and lifetimes of technologies implemented. Within this study, no research on these data has been performed. Instead, data from already existing and sometimes extensive studies have been used, and their magnitudes have been evaluated if credible and sensible. This has been done for all the investigated renewable technologies. The procedure is exemplified on the compiled set of data used for wind energy, and a similar approach has been used to evaluate the data for the other energies. interactions of Eqs. 2, 3, 4, 5, 6, 7, 8, 9, 10, 11, 12, 13, 14. The ellipses connected by curved arrows show some "key quantities", derivable from the system variables (Eq. 1)

\section{Technical functions}

Lifetime distribution of wind turbines $k\left(t, t^{\prime}\right) \quad$ Turbines have a certain lifetime, but not all will fail at the same time. This fact is taken into account by choosing a Gaussian distribution of lifetime, namely (see Fig. 3a, Table 1):

$k\left(t, t^{\prime}\right)=\frac{1}{N_{0}} \mathrm{e}^{\left(t t^{\prime} \tau\right)^{2} / 2 \sigma^{2}}$,

$N_{0}$ is the normalization factor. $\tau$ is the average lifetime and $\sigma$ is its standard deviation. For a more detailed discussion of this lifetime distribution see Baccini and Bader (1996) and Zeltner et al. (1999).

Equation 15 describes the lifetime distribution by the two parameters $\tau$ and $\sigma$. It is assumed that average lifetime of a wind turbine is 17.5 years, assuming that rotor blades will be replaced two times, and parts of generators and electronics will be replaced as well. After that time, even functioning turbines will be replaced by more modern and/or more efficient and/or safer turbines. The width $\sigma$ of the distribution is assumed to be 7.5 years. It means that some turbines 


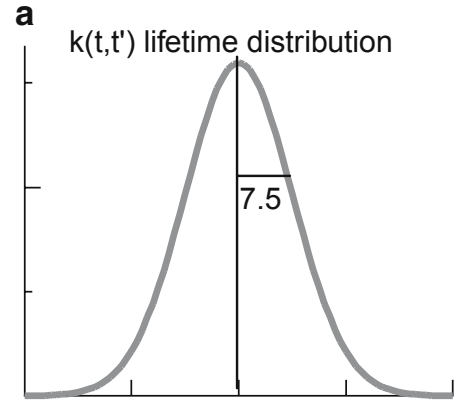

17.5
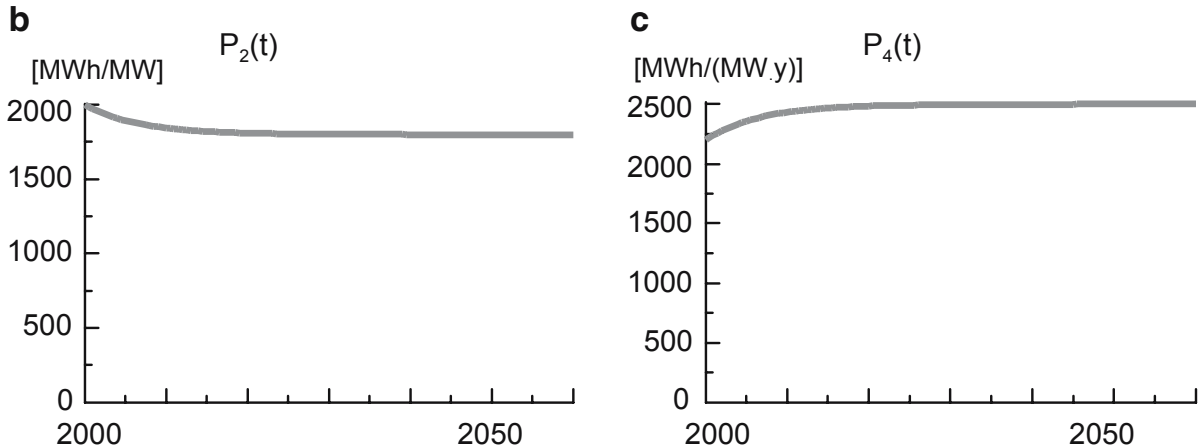

Fig. 3 Technical parameter functions for the subsystem wind: a lifetime distribution $k\left(t, t^{\prime}\right)$, b specific energy requirement for manufacturing $P_{2}(t)$ and $\mathbf{c}$ specific energy production $P_{4}(t)$

will already be replaced after 10 years or less, and some will last as long as 25 years or more. Again, this is certainly a conservative assumption, since it may well be that along the learning curve reliability will also increase.
Specific energy quantities $P_{2}, P_{3}, P_{4}$ For the specific energy requirement for manufacturing $P_{2}(t)$, for operation $P_{3}(t)$ and the specific energy generation per windturbine unit $P_{4}(t)$ an exponential decrease or increase has been assumed (see Fig. 3b, c, Table 1):
Table 1 Parameter values for the different parameter functions for wind powerplants
Technical parameters $k\left(t, t^{\prime}\right)$

$\tau$

$\sigma$

$P_{2}(t)$

$a_{2}$

$b_{2}$

$\alpha_{2}$

$P_{3}(t)$

$a_{3}$

$b_{3}$

$\alpha_{3}$

$P_{4}(t)$

$a_{4}$

$\alpha_{4}$

$P_{9}(t)$

$a_{9}$

$P_{10}(t)$

$a_{10}$

"Stakeholder related"

parameters

$P_{1}(t)$

$p_{\text {init }}$

$p_{\text {sat }}$

$\alpha$

$t_{\text {turn }}$

$a_{1}$

$t_{1}$

$t_{0}$

$P_{5}(t)$

$a_{5}$

$b_{5}$

$\alpha_{5}$

$P_{6}(t)$

$a_{6}$

$b_{6}$

$\alpha_{6}$

$P_{7}(t)$

$a_{7}$
$P_{8}$
Residence time distribution

17.5 year

7.5 year

Specific energy for manufacturing

1,800 $\mathrm{MWh} \mathrm{MW}^{-1}$

$200 \mathrm{MWh} \mathrm{MW}^{-1}$

0.15 year $^{-1}$

Specific energy for operation

40 MWh (MW year) ${ }^{-1}$

$15 \mathrm{MWh}(\mathrm{MW} \text { year })^{-1}$

0.15 year $^{-1}$

Specific energy generation

2,500 $\mathrm{MWh}$ (MW year) ${ }^{-1}$

$300 \mathrm{MWh}^{(\mathrm{MW} \text { year })^{-1}}$

0.15 year $^{-1}$

Specific $\mathrm{CO}_{2}$ equivalent for manufacturing

$611 \mathrm{~kg} \mathrm{MWh}^{-1}$

Specific $\mathrm{CO}_{2}$ equivalent for operation

$611 \mathrm{~kg} \mathrm{MWh}^{-1}$

Moderate

Fast

Implementation function

$1159.6 \mathrm{MW}$

1,800,000 MW

0.148439 year $^{-1}$

2030

972.26 MW

$1,800,000 \mathrm{MW}$

0.291828 year $^{-1}$

2016.02

130.65 year $^{-1}$

1987.59

1976.72

Specific cost for manufacturing

$800,000 \$ \mathrm{MW}^{-1}$

$200,000 \$ \mathrm{MW}^{-1}$

0.15 year $^{-1}$

Specific cost for operating

$40,000 \$$ (MW year) $^{-1}$

$30,000 \$$ ( MW year) $^{-1}$

0.15 year $^{-1}$

Interest

0.05

Repayment rate $1 / 12.5$ year 
$P_{i}(t)=a_{i}+b_{i} \mathrm{e}^{\alpha_{i} t}$,

where $i=2,3,4$ for $P_{2}(t), P_{3}(t)$ and $P_{4}(t)$.

The parameter $a_{i}$ in Eq. 16 is the saturation value for the distant future $t \rightarrow \infty$ and $a_{i}+b_{i}$ represents the initial value at $t=0 . \alpha_{i}$ represents the reciprocal decrease or increase time characteristic.

The parameter functions (Eq. 16) reflect the fact that turbines have become more energy efficient in manufacturing and operation in the past and, following the learning curve, will continue to improve in the future. Efficiency of machines will also still slightly improve over time, because improved blade design will make optimal use of aerodynamics, and drive losses may become smaller as gearless turbines may evolve. However, this gain will be weakened due to the fact that good accessible wind sites will soon be used up and sites with less optimal wind regime have to be tapped.

Specific energy to manufacture and install wind turbines $P_{2}(t)$ This will decrease from the current value of 2,000 MWh MW ${ }^{1}$ installed wind turbine to 1,800 MWh. Thus $a_{2}=1,800 \mathrm{MWh} \mathrm{MW}{ }^{1}$ and $b_{2}=200 \mathrm{MWh}$ MW ${ }^{1}$, respectively. The decrease is the result of larger wind turbine sizes, larger and more efficient mass production and more efficient turbines (better aerodynamics, power tracking and less losses in gear transmission).

Specific energy for operation $P_{3}(t)$ The current value is $55 \mathrm{MWh} \mathrm{MW}{ }^{1}$ installed per year, based on assumed replacement and maintenance procedures. This accounts for the energy for services (cranes, trucks etc.) as well as for spare parts and lubricants. It is assumed to decrease to $40 \mathrm{MWh}$ (MW year) ${ }^{1}$ due to improvements. Thus $a_{3}=40 \mathrm{MWh}$ (MW year) ${ }^{1}$ and $b_{3}=15 \mathrm{MWh}$ (MW year) ${ }^{1}$.

Wind energy generation per year $P_{4}(t) \quad$ In the literature and the technical specifications this quantity is expressed in full load hours per year. Full load hours is the value the unit would have to operate under nominal power to produce the assumed annual energy production over 1 year, which equals $8,760 \mathrm{~h}$, using $24 \mathrm{~h} \times 365$ days. The initial value for the year 2000 is $2,200 \mathrm{~h}$ full load operation per year and will increase to $2,500 \mathrm{~h}$ per year by 2050. The reason (Neumann 2003) is as follows: (1) Although for the initial installation phase, the best sites have been taken based on criteria of accessibility (road and grid), the better sites are still to be explored (more remote sites, today still not easily reached by grid and/or road), such as offshore, remote areas in Patagonia (Chile and Argentina). (2) Efficiency will still improve over time (less gear transmission losses, better blade aerodynamics, variable speed etc).

The corresponding specific energy generation is the product of full load hours multiplied by the energy power, resulting in 2,200 MWh (MW year) ${ }^{1}$ for the year 2000 and $2,500 \mathrm{MWh}$ (MW year) ${ }^{1}$ for the future. Therefore $a_{4}=2,500 \mathrm{MWh}$ (MW year) ${ }^{1}$ and $b_{4}=-300 \mathrm{MWh}$ (MW year) ${ }^{1}$. For the reciprocal time characteristic a value of $\alpha_{2}=\alpha_{3}=\alpha_{4}=0.15$ year ${ }^{1}$ has been assumed, which is typical and reasonable for such industrial processes (Real 1998). The influence of other values on the results will be discussed below.

The parameters for $P_{2}, P_{3}$ and $P_{4}$ estimated in this sense are listed in Table 1.

Specific $\mathrm{CO}_{2}$ equivalent emissions $P_{9}, P_{10}$ The specific $\mathrm{CO}_{2}$ equivalent emissions during manufacturing and operation, $P_{9}(t)$ and $P_{10}(t)$, are assumed to be constant as a function of time:

$P_{i}(t)=a_{i}$,

where $i=9,10$.

Manufacturing, installing, operating and finally dismantling a turbine will need energy and contribute, therefore, to some extent to greenhouse gas emissions. The current value $P_{i}(0)$ is based on the current "energy mix" (Frischknecht 2001). The "energy mix" is defined as the energy share of the different types of electrical power plants for a country or a region. This "energy mix" improves continuously towards more renewable energy. The reason is that each installed turbine will yearly produce a large amount of energy, substituting energy derived from other sources. This means that the parameter function $P_{9}(t)$ and $P_{10}(t)$ should slowly decrease with increasing time, if this effect is taken into account. As a first approximation, this effect has been neglected. This is a "conservative" assumption, since this negligence only makes the " $\mathrm{CO}_{2}$ balance" for the implementation and operation of renewable energies worse than without this assumption.

Note that all greenhouse gases are expressed in $\mathrm{CO}_{2}$ equivalents, taking into account other gases such as methane, as defined in IPCC (2001). It is assumed that wind turbines will be manufactured in Europe or in a country with a similar "energy mix" with regard to carbon burden per kWh. This accounts for $611 \mathrm{~g} \mathrm{kWh}{ }^{1}$ in Europe (Frischknecht 2001). Thus $a_{9}=a_{10}=$ $611 \mathrm{~kg} \mathrm{MWh}^{1}$ (see also Table 1)

\section{"Stakeholder related" function}

Implementation function $P_{1}(t)$ Ender $(2003,2004)$ and Gutschner (2004) presented time series for the implementation of wind turbines for the period 1985-2003. According to Ender (2004) the actual installed capacity at the end of the year 2003 is 40,300 MW.

The potential for wind energy production plants is estimated to be $1.8 \times 10^{6} \mathrm{MW}$. The reasons are as follows: (1) The outlook for 2007 worldwide is $83,000 \mathrm{MW}$, whereby 58,000 MW is in Europe alone (BTM Consult 2003). Assuming that by then the worldwide potential has hardly been explored, a 20 -fold potential of this potential for worldwide implementation seems more 
than likely. (2) The World Energy Assessment (WEA 2000) estimates the worldwide potential to be $640 \times 10^{18} \mathrm{~J}$, based on assumed wind power density $>250-300 \mathrm{~W} \mathrm{~m}^{2}$ at $50 \mathrm{~m}$ height (Grabb 1993). From this estimation, the Group of the World Energy Council concludes a resource potential of about $10 \%$, namely $68 \times 10^{18} \mathrm{~J}$ (WEA 2000, p 164). Assuming the conservative value of 2,000 full load hours, this converts into an installed capacity of $9.5 \times 10^{6} \mathrm{MW}$. The assumed capacity in this study is therefore about five times smaller than estimated in the WEA study, and therefore rather conservative.

Based on the time series mentioned above and the assumed potential, a curve fit has been performed. As the implementation function, a logistic (sigmoidal) or the more general linear-logistic growth curve has been chosen. The reason is that such growth curves are typical for industrial goods as well as for biological systems (Fischer 1970).

The logistic growth is characterized by a slow but exponential introduction of wind power plants followed by a steep linear growth in the middle and a saturation towards the end of the implementation time.

Mathematically this behaviour can be described as follows:

$P_{1}(t)=p_{\text {init }}+\frac{p_{\text {sat }}-p_{\text {init }}}{1+\mathrm{e}^{\alpha\left(t t_{\text {turn }}\right)}} \quad$ logistic growth,

$p_{\text {init }}$ is the initial value in the distant past $t \rightarrow-\infty, p_{\text {sat }}$ the saturation value in the distant future $t \rightarrow \infty, \alpha$ is proportional to the maximal growth rate and $t_{\text {turn }}$ is the turning point of the growth curve, respectively. For reason of simplicity, $\alpha$ will be denoted simply as growth rate.

The linear-logistic growth is a linear growth at the beginning of the growth period, followed by a logistic growth. The transition point is characterized by a continuous slope.

Mathematically it can be described as follows:

$P_{1}(t)=\left\{\begin{array}{cc}a_{1}\left(t-t_{0}\right) & t_{0} \leq t \leq t_{1} \\ p_{\text {init }}+\frac{p_{\text {sat }} p_{\text {init }}}{1+\mathrm{e}^{\alpha\left(t t_{\text {turn }}\right)}} & t_{1} \leq t\end{array}\right.$

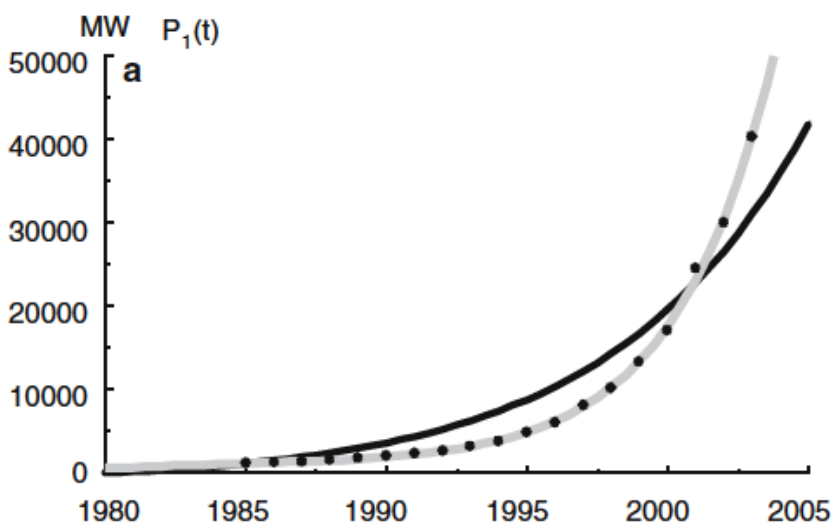

The time points $t_{0}$ and $t_{1}$ are the starting point of the implementation and the transition point, respectively. (The transition condition requires that $P_{1}$ and $\mathrm{d} P_{1} / \mathrm{d} t$ are continuous at $t=t_{1}$.)

Best results for the non-linear fit were obtained for a "growth rate" $\alpha$ of 0.292 and a turning point $t_{\text {turn }}$ of 2016. This would result in a quite fast implementation compared to the normal "growth rates" of 0.15 of industrial products. Therefore, the best fit has been used for the scenario "fast implementation". For the standard scenario or "moderate implementation" a turning point $t_{\text {turn }}$ of 2030 has been chosen, leading to a fitted growth rate $\alpha$ of 0.148 . Both implementation curves are shown in Fig. 4. For the values of the parameters see Table 1.

Specific costs $P_{5}(t)$ and $P_{6}(t) \quad$ For the specific costs of manufacturing $P_{5}(t)$ and for operation $P_{6}(t)$ an exponential decrease similar to $P_{2}(t)$ and $P_{3}(t)$ above has been assumed. This is based on the expectation that wind turbines will become more cost effective in the future in manufacturing and operation. Today, a generally accepted figure for installation cost is 1,000 US\$ $\mathrm{kW}^{1}$ installed, and it is assumed that this average value will decrease along the learning curve to $800 \mathrm{US}^{\mathrm{kW}}{ }^{1}$ [700 Euro $\mathrm{kW}{ }^{1}$ (Neumann 2003)]. Since all values are in dollars, there is an uncertainty based on fluctuating exchange rate and origin. In Germany, for example, installations are less expensive than in Greece due to a different scale of implementation and infrastructure.

From this value, it follows $a_{5}=\$ 800,000 \mathrm{MW}{ }^{1}$ and $b_{5}=\$ 200,000 \mathrm{MW}{ }^{1}$. For the reciprocal time characteristic $\alpha_{5}, 0.15$ year ${ }^{1}$ has been assumed for the same reasons as for the parameter functions $P_{2}(t), P_{3}(t)$ and $P_{4}(t)$.

It is assumed that the average maintenance costs are initially $7 \%$ per year of installation cost, resulting in 70 US\$ (kW year) ${ }^{1}$. This will reduce to 40 US\$ $(\mathrm{kW}$ year) ${ }^{1}$ by 2050 , due to a moderate learning curve also in the maintenance. Included in this figures are maintenance crew, spare part costs, and insurance costs, tax

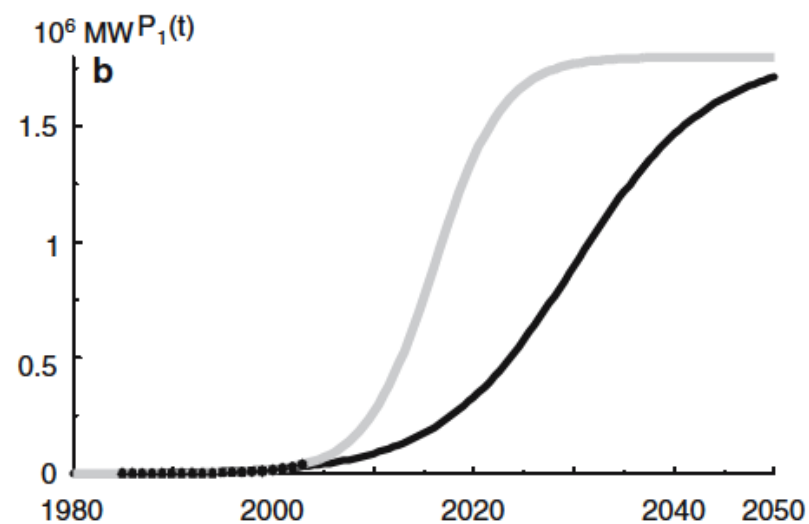

Fig. 4 Implementation function $P_{1}(t)$ for moderate and fast implementation for the subsystem wind 
and administration, but no service costs for capital. It follows $a_{6}=\$ 40,000$ (MW year) ${ }^{1}$ and $b_{6}=\$ 30,000$ (MW year) ${ }^{1}$. Similar as above $\alpha_{6}=0.15$ year ${ }^{1}$ is assumed.

For the corresponding parameter values see Table 1 .

Interest $P_{7}(t)$ The real interest is $5 \%$. It is assumed that this value will remain constant, and will be offset by inflation rate, assuming real interest rate $=$ nominal interest minus inflation rate. These values differ from country to country and from year to year and are dependent on parameters such as: percentage of debt in capital structure $(\%)$, debt interest rate $(\%)$, debt repayment period (years), royalties ( $\%$ of gross revenue), federal income tax rate $(\%)$, state income tax rate $(\%)$, sales tax rate $(\%)$, expected inflation rate $(\%)$, investment tax credit $(\%)$, production tax credit (cents $\left.\mathrm{kWh}{ }^{1}\right)$, plant size $(\mathrm{kW})$, average annual capacity factor $(\%)$, power plant costs $\left(\$ \mathrm{~kW}^{1}\right)$, taxable amount (for sales tax), transmission and interconnect, other capital costs, interest rate during construction (\%), debt service reserve, debt-related fees, equity-related fees (such as tax advice), equity-related fees (such as organizational fee), equity-related fees (other), annual fixed operation and maintenance $\left(\$ \mathrm{~kW}{ }^{1}\right)$.

In the past, these factors were responsible for quite strong fluctuations in the interest. However, over the longer periods of time considered in this study $(\sim 20$ 50 years), these fluctuations balanced more or less out in the past. Therefore, for ease of comparison of the various technologies, a 5\% interest rate has always been assumed. At the present time, interest rates are much lower in developed countries.

Repayment rate $P_{8}\left(t, t^{\prime}\right) \quad$ For the repayment of capital, a fixed time period of 12.5 years has been assumed. This value can be defended, if lifetime is 17.5 years. Still, finding capital for a time period greater than 10 years is much more difficult and also expensive, since longer write off times enhance uncertainties and reflect directly on the interest rate.

The repayment rate has been defined according to two different strategies, namely: (1) constant repayment rate and (2) constant sum of repayment rate and cost of interest per year.

To conclude the calibration it must be stressed that all assumptions on technical parameters are "conservative". It means that they are realistic from the current state of technology and do not require unrealistic technological jumps.

The calibration for the other subsystems is similar. The results are shown in Fig. 5 and Table 2. As implementation functions, based on the available data, besides the logistic and linear logistic, a double-logistic function has proven to be appropriate (for the case of hydropower).

The parameter values for all other parameter functions except $P_{1}$ are listed in Table 2 .

\section{Results and discussion}

Based on the calibrated model, numerous simulations, each representing a possible future development strategy (scenario), were carried out. It turned out that the key parameter is the implementation time, concerning possible limiting factors.

Wind subsystem

In Fig. 6, results for some key variables for the subsystem wind for moderate $(\approx 60$ years $)$ and fast ( $\approx 30$ years) implementation are shown.

According to their behaviour as a function of time, the variables shown in Fig. 6 can roughly be classified into the following three groups.

Variables which are very sensitive to implementation time: this group covers the number of new installations per year, the energy and costs for manufacturing/installation, the $\mathrm{CO}_{2}$ caused by manufacturing/installation and the capital. All of them show overshooting and oscillation for fast implementation. The reason is that for implementation times comparable or shorter than the average lifetime, $\tau$, the capacities (production, energy and money) needed for the "implementation" period are much larger than those needed for the "replacement" or "renewal" period. This effect has already been discussed in previous work (Real 1998; Binder et al. 2001; Hug et al. (2004).

The following simple argument can help to understand this phenomenon.

The number of new installations per year can roughly be estimated for these two periods as follows: "replacement" period:

$I=\frac{p_{\mathrm{sat}}}{\tau}$.

"implementation" period: At the turning point (steepest slope) of the implementation period, the number of "pure" new installations (without replacement) is simply:

$I=\frac{p_{\text {sat }}-p_{\text {init }}}{4} \alpha$

which follows directly by differentiating the logistic growth curve (Eq. 18). It can be shown that $4 / \alpha$ is proportional to the implementation time for logistic growth curves. From Eqs. 20 and 21, it follows that the number of new installations per year is inversely proportional to the average lifetime and the implementation time for the two periods, respectively. Therefore, implementation times shorter than the average lifetime result in higher production capacities needed during the implementation phase. Using formula Eqs. 20 and 21 and the parameter values of Table 1, the estimated number of new installations per year are: "replacement" period: $I=103,000$, "implementation" period: $I=67,000$ (moderate) and $I=131,000$ (fast). 

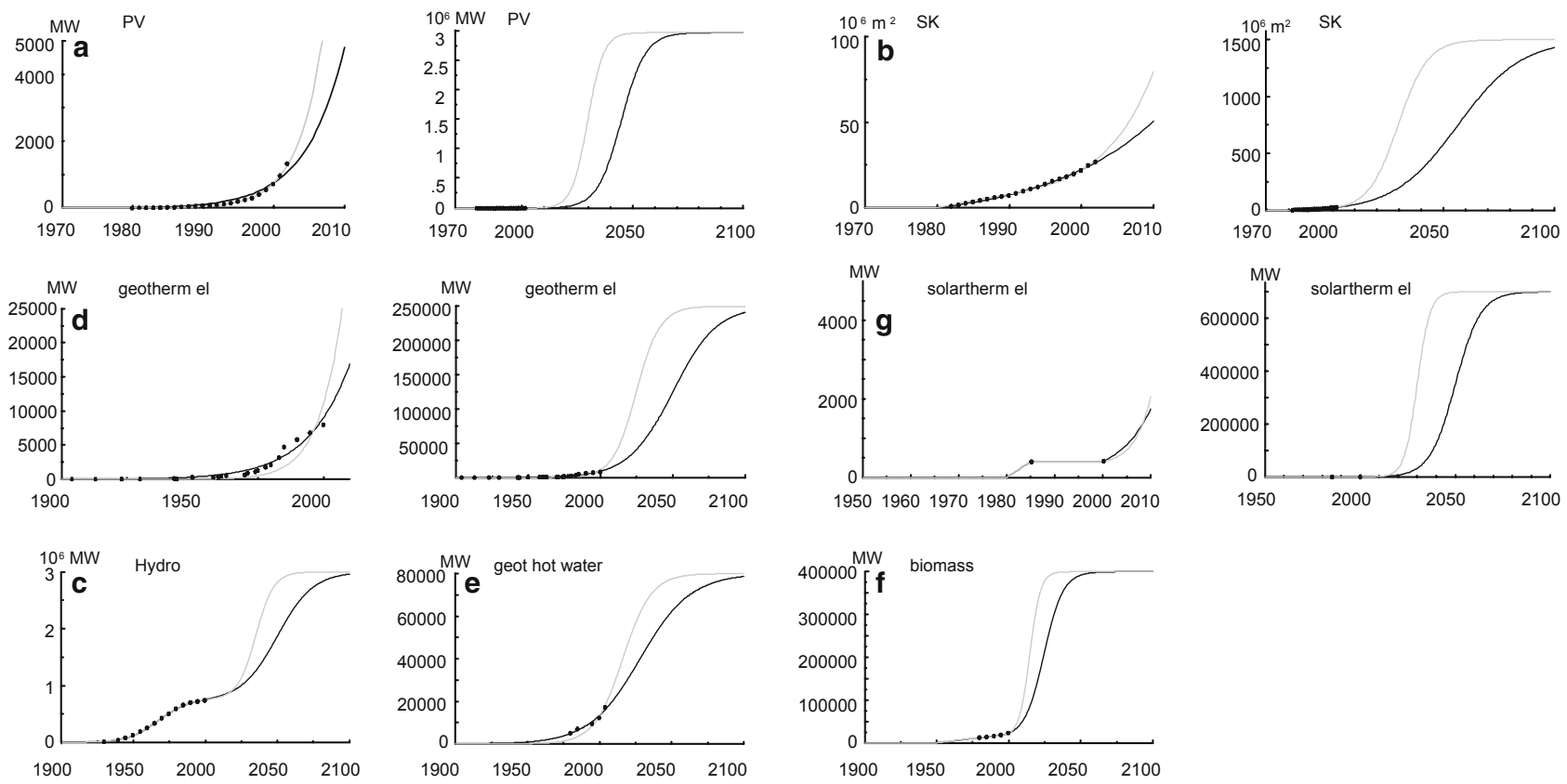

Fig. 5 Implementation functions $P_{1}(t)$ for moderate and fast implementation for the subsystems: PV, solar collectors (SK), geothermal electricity, solarthermal electricity, hydropower, geothermal hot water and biomass (electricity)

Table 2 Parameter values for the different parameter functions for PV, solar collectors, hydropower, geothermal electricity, geothermal direct heat, solarthermal electricity and biomass electricity

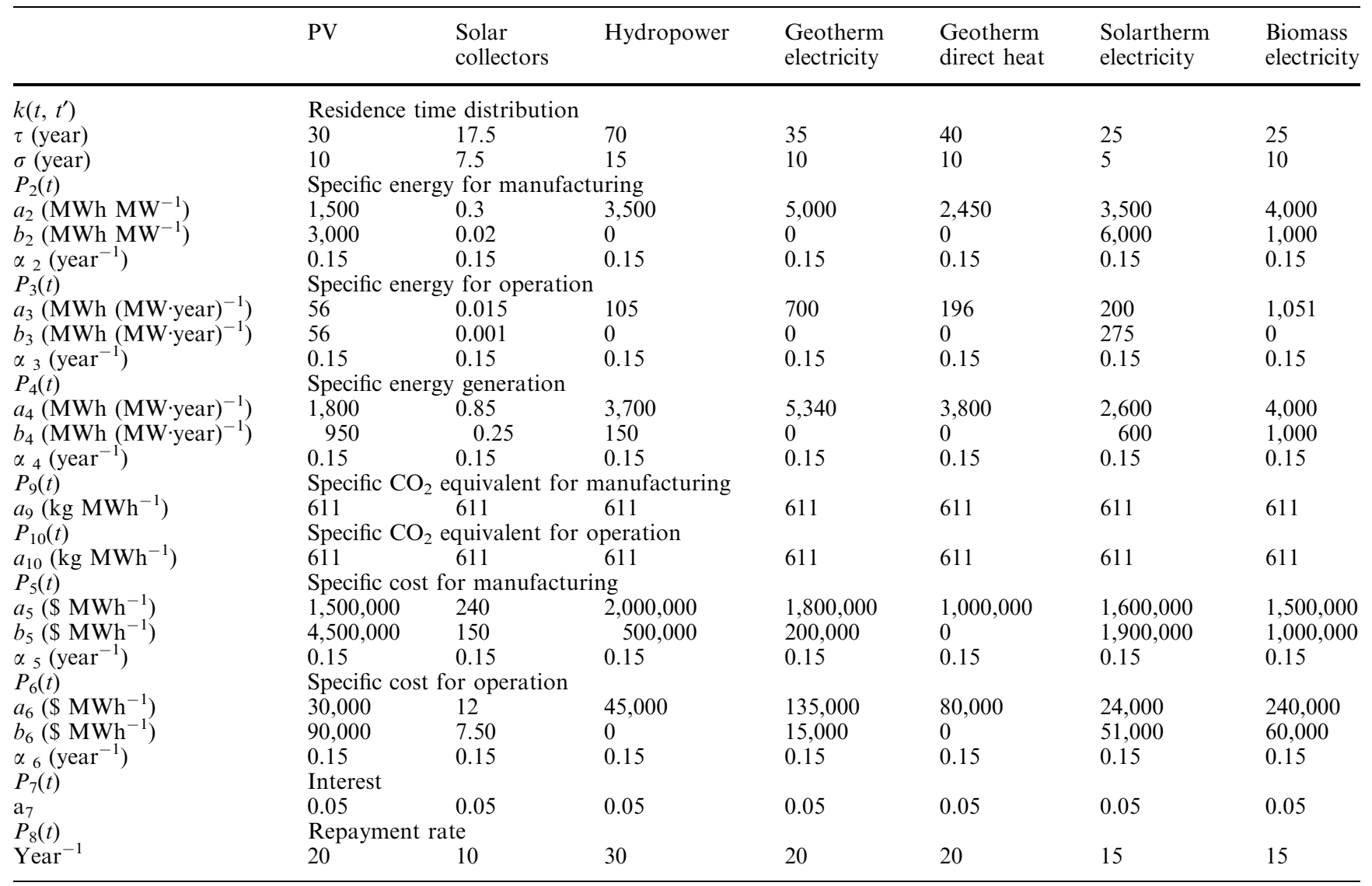

The units for solar collectors for $P_{3}, P_{4}, P_{4}$ and $P_{6}$ are per $\mathrm{m}^{2}$ instead of per MW 

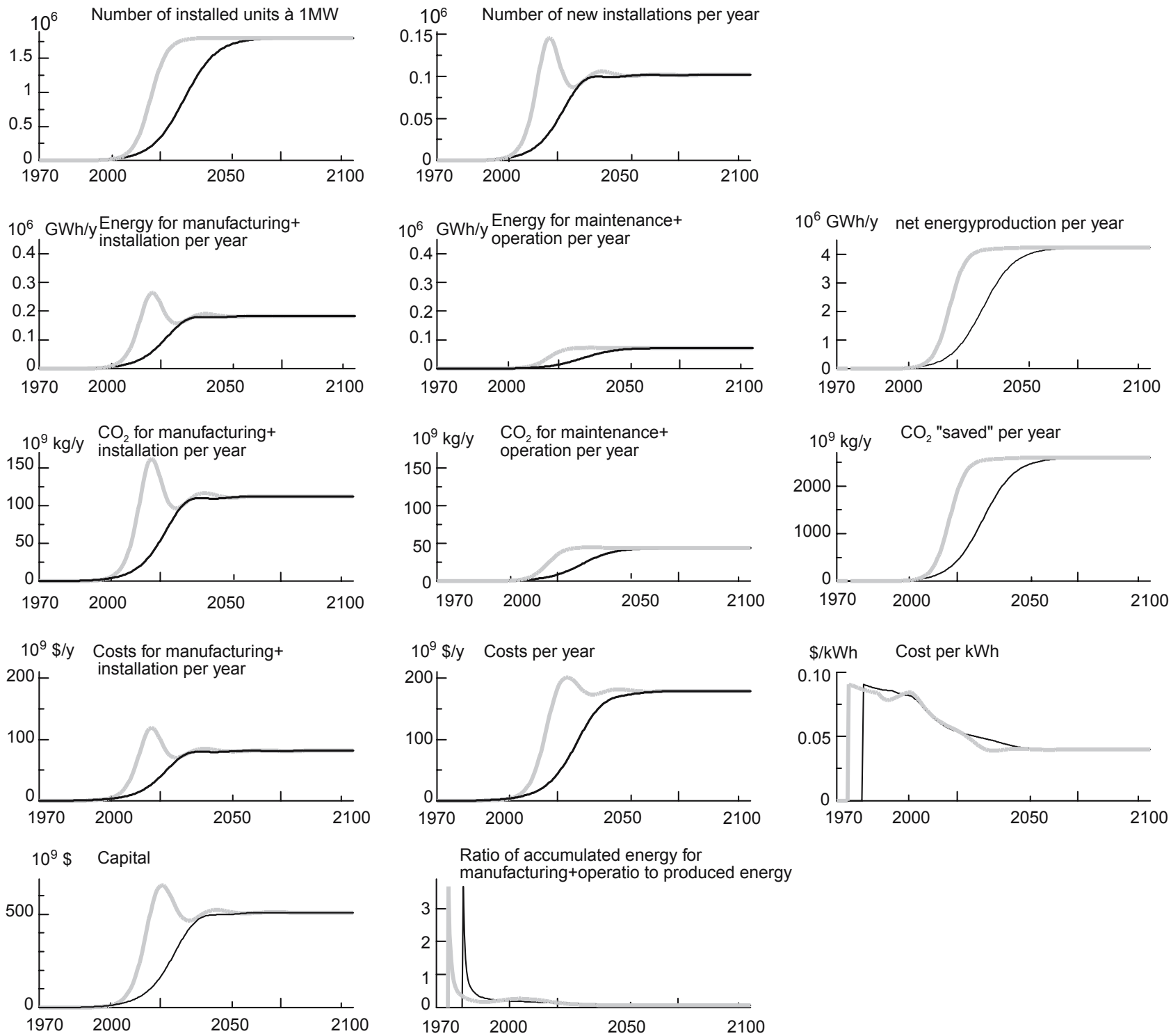

Fig. 6 Simulation results for key variables for the subsystem wind: number of installed units of $1 \mathrm{MW}$, number of new installations of $1 \mathrm{MW}$ year ${ }^{-1}$, energy used for manufacturing/installation and operation per year, net energy generation per year, $\mathrm{CO}_{2}$ emitted by manufacturing/installation and operation per year, $\mathrm{CO}_{2}$ "saved" per year, costs for manufacturing/installation per year, sum of cost for operation, interest and repayment per year, the cost per produced energy unit, capital and ratio of accumulated energy for manufacturing and operation to produced energy
The number of new installations per year $[I(t)]$, in Fig. 6 indicates that the industrial production capacity could be one of the limiting factors. Indeed this capacity would have to increase continuously within the next 30 years from the current value of 10,000 installations of $1 \mathrm{MW}$ in the year 2003 to about 100,000 installations per year, even for moderate implementation. Whether this is feasible or not has to be discussed carefully by the stakeholders involved. This analysis must of course include a discussion of all the manufacturing and implementation processes. If it turns out that this implementation strategy is not feasible, different strategies have to be evaluated. The parameter functions in discussion are the implementation $P_{1}(t)$ and the lifetime distribution $k\left(t, t^{\prime}\right)$ (Eqs. 2, 3, 4). The study here shows that the most sensitive parameters are the potential $p_{\text {sat }}$, the average lifetime $\tau$ and the implementation time $1 / \alpha$ (Eqs. 20, 21). As an example, the maximum of the needed production capacity for some combination of these parameters is shown in Table 3.

Figure 6 shows that the energy needed for manufacturing and operation is less than $7 \%$ of the energy generated by the wind turbines on a long timescale. Only at the beginning of the implementation phase for a short-time period, the production is less than the energy used for manufacturing and operation. The same is true for the $\mathrm{CO}_{2}$ emitted by the manufacturing and operation in comparison with the $\mathrm{CO}_{2}$ saved. By "saved" we mean 
Table 3 Maximum needed production capacity $I_{\max }$ in MW year ${ }^{-1}$ for different combinations of the sensitive para meters "implementation time" (fast, moderate), average lifetime $(\tau)$ and potential $p_{\text {sat }}$

\begin{tabular}{llll}
\hline Scenario & $p_{\text {sat }}(\mathrm{MW})$ & $\tau($ years $)$ & $I_{\max }\left(\mathrm{MW} \mathrm{year}{ }^{-1}\right)$ \\
\hline Moderate & $1.8 \times 10^{6}$ & 17.5 & 102,000 \\
Fast & $1.8 \times 10^{6}$ & 17.5 & 146,000 \\
Moderate & $1.8 \times 10^{6}$ & 30 & 79,000 \\
Fast & $1.8 \times 10^{6}$ & 30 & 138,000 \\
Moderate & $10^{6}$ & 17.5 & 57,000 \\
Fast & $10^{6}$ & 17.5 & 81,000 \\
\hline
\end{tabular}

the $\mathrm{CO}_{2}$ difference relative to what would have been emitted by producing the electrical energy with fossil power plants instead of wind turbines.

Variables which are intermediately sensitive to implementation time: those are the energy for operation, the net energy production, the $\mathrm{CO}_{2}$ caused by operation, the $\mathrm{CO}_{2}$ saved and the costs per year. Since they are directly related to the number of installed turbines, they show more or less the same behaviour as this quantity. In particular, shorter implementation times lead to a steeper growth, but no overshooting occurs.

Variables which are not sensitive to implementation time: the costs per produced $\mathrm{kWh}$ and the ratio of accumulated energy for manufacturing and operation to accumulated produced energy. These two are more or less independent of the implementation time and decrease continuously to a certain level. For the costs per $\mathrm{kWh}$ this reflects the assumption that the costs for manufacturing/installation and operation decrease with increasing number of installations.

Influence of the time characteristics $\alpha_{2}, \alpha_{3}, \alpha_{4}, \alpha_{5}$ and $\alpha_{6}$ For the calculations presented in Fig. 6 a value of 0.15 has been assumed for these $\alpha_{i}$ 's (Table 2). Assuming a lower value, for instance 0.05 , would mean a slower technical innovation for the specific energy requirement for manufacturing $P_{2}(t)$, for operation $P_{3}(t)$, for the specific energy generation $P_{4}(t)$, for the specific cost for manufacturing $P_{5}(t)$ and for operation $P_{6}(t)$. This would result in slightly increased peaks in energy requirement and costs for manufacturing and operation and a slightly retarded increase of the net produced energy. However, it must be pointed out that this is not a limitation for the implementation.

The result for the other subsystems show a similar behaviour.

\section{System of renewables}

The variables in Fig. 7 are the key variables describing the "energy", induced " $\mathrm{CO}_{2}$ " and "financial" household of the system of renewables. This includes wind, PV, solar collectors, solar thermal electricity, biomass for electricity, geothermal electricity and geothermal heat power generation.
The installed overall capacity and the new installations per year are not discussed here. The reason is that these quantities have to be discussed for each type of energy supply separately, since each type of energy requires its specific technique and manufacturing facility. The characteristic of the patterns in Fig. 7 is similar to that already discussed for the subsystem wind in Wind subsystem section.

A careful analysis of Fig. 7 led to the following results:

Energy The energy needed for manufacturing and operation is less than $7 \%$ of the produced energy. Therefore, the energy needed for manufacturing is certainly not a limitation to the large scale implementation.

The energy produced per year after the renewables have reached their potential would be about $27 \times 10^{12} \mathrm{kWh}$ year ${ }^{1}$ (Fig. 7). This corresponds to a (permanent) average power of $0.44 \mathrm{~kW}$ per person on the basis of a world population of 7 billions. According to OECD/IEA (2004), the estimated world energy consumption in 2001 was about $17,000 \mathrm{kWh}$ per person corresponding to an average power consumption of $1.94 \mathrm{~kW}$ per person ( $2 \mathrm{~kW}$-society). This is about five times more than the production by renewables presented here [For the term kW-society, see Hug et al. (2004) and references therein].

Costs and capital According to Fig. 7, the prime costs for the energy would be not more than $0.057 \$ \mathrm{kWh}{ }^{1}$ and stabilize at $0.04 \$ \mathrm{kWh}^{1}$ on the long timescale. This is comparable to the costs for production of electricity using non-renewable energies.

The investment per year (Fig. 7) shows a peak height of 360 and 180 billion dollar per year for fast and moderate implementation, respectively. On the longterm scale, it tends towards zero, since repayment and new investment balance out. On the basis of the actual world population of 7 billion the peak height would be $\$ 50$ and \$26 per person per year. Compared to the other important investments in buildings and cars, this is a neglectable amount.

The capital used to finance the new implementations reaches a peak of $\$ 6,000$ (fast) and $\$ 4,700$ billion (moderate implementation). On the long-term scale, it evens out at about $\$ 4,100$ billion. This corresponds to a peak value of $\$ 860$ (fast) and $\$ 670$ per person and an equilibrium value of $\$ 590$ per person. Similarly, as seen above for the investment per year, the capital per person is an order of magnitude smaller than the capital bound in buildings, infrastructure and cars.

If the repayment time periods are reduced, less capital to finance the new installations is needed. However, the costs per $\mathrm{kWh}$ are slightly increased at the beginning of the implementation phase and reduced on a long timescale. The reasons are higher repayment amounts at the beginning and smaller interest amount on the long term. For example, halving the repayment rates of Table 1 and 2 induces halving the capital. The increase of the 
costs per $\mathrm{kWh}$ at the beginning of the implementation period is about $20 \%$ and the reduction is about $10 \%$ after the implementation period.

$\mathrm{CO}_{2}$ Figure 7 shows that the amount of saved $\mathrm{CO}_{2}$ increases to a saturation value of about 15 billion tons $\mathrm{CO}_{2}$ per year. Compared to the total emissions estimated for the year 2001 of 24 billion tons (3.4 tons per person) (World energy outlook 2000) this is quite considerable. With the actual world population of 7 billion this would result in a reduction of 2 tons per person per year.'

\section{Conclusions}

The dynamic simulations presented and discussed in this study allow to answer three main questions.

What are the limitations for large scale implementation of renewables? The dynamic simulation allowed the identification of required industrial growth and possible relevant limitations. From the possible three limiting factors: industrial manufacturing capacity, energy and financial requirement, only the manufacturing capacity turned out to be a limitation. As explained above, the necessary industrial capacities have to be discussed for each type of energy separately. The example of wind energy shows clearly that fast implementation (growth rates of 0.3 ) requires large overcapacities during the "implementation" period. For the "replacement" period, following the implementation period, these overcapacities would have to be reduced drastically. This would have undesired socio-economic consequences for the involved employees and trained installation specialists (see also Hug et al. 2004). Which growth rates are feasible has to be discussed carefully. The implementation of hydropower in the last century shows that growth rates of 0.1 are possible. This value corresponds to moderate implementation.

Development of investment and costs? This question has been discussed in detail above resulting in low investment costs per capita and a cost of about $\$ 0.04 \mathrm{kWh}{ }^{1}$ electricity. This is comparable to the costs of non-renewable energy systems.

Impact on $\mathrm{CO}_{2}$ emission? The large scale implementation of renewables would result in a considerable reduction in emissions, namely by about 2 tons per person per year on the basis of 7 billion people.

It is obvious that this relatively simple dynamic model is not able to cover all aspects and problems
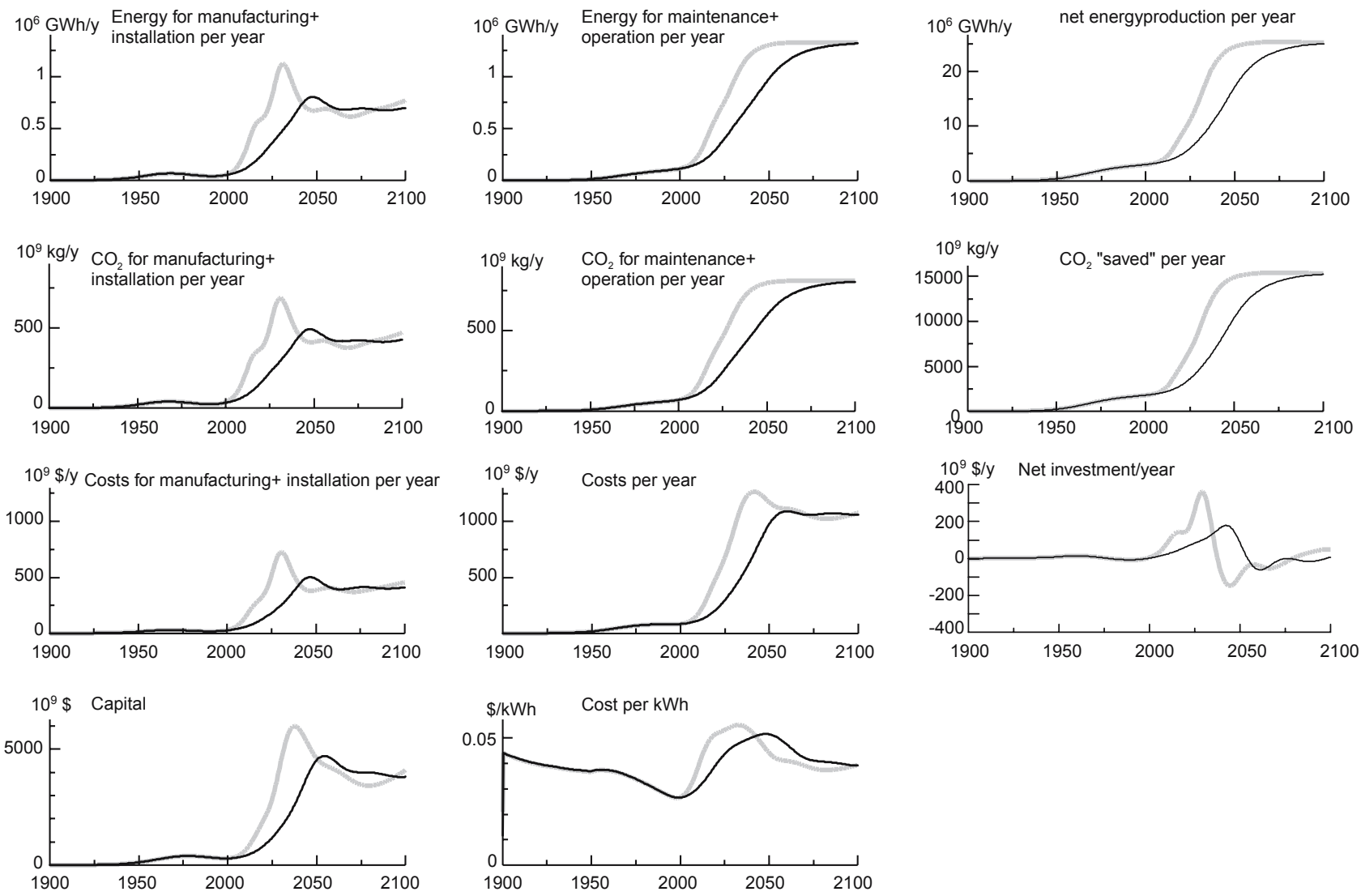

Fig. 7 Simulation results for key variables for the system of renewable: energy used for manufacturing/installation and opera tion per year, net energy generation per year, $\mathrm{CO}_{2}$ emitted by manufacturing/installation and operation per year, $\mathrm{CO}_{2}$ "saved" per year, costs for manufacturing/installation per year, sum of cost for operation, interest and repayment per year, net investment per year, capital and the cost per produced energy unit 
concerning an implementation of renewables on a large scale. For instance all the problems of industrial manufacturing and installation, connections to the grid and the energy distribution cannot be studied. However, the model can answer the question of possible limitations and in particular show the consequences of different implementation times.

Acknowledgements We thank M. Bader for helpful discussions, Dr. M. Borsuk for helpful comments and carefully reading the manu script and the BUWAL (Bundesamt für Umwelt, Wald und Landschaft, Switzerland) for financial support of the project.

\section{References}

Baccini P, Bader H P (1996) Regionaler Stoffhaushalt. Spektrum Akad.Verlag, Heidelberg

Bader H P, Real M, Scheidegger R (2003) Large scale im plementation of solar home systems in remote, rural areas. Clean Technol Environ Policy 6:18 25

Binder C, Bader H P, Scheidegger R, Baccini P (2001) Dynamic models for managing durables using a stratified approach: the case of Tunja, Columbia. Ecol Econ 38:191 207

BTM Consult (2003) International wind energy development. Ringkobing, Dänemark March 2003

Ender C (2003) Internationale Entwicklung der Wind energienutzung mit Stand 31.12.2002. DEWI (Deutsches Windenergie Institut) Magazin 23:19 26

Ender C (2004) Internationale Entwicklung der Wind energienutzung mit Stand 31.12.2003. DEWI (Deutsches Windenergie Institut) Magazin 25:26 31

Fischer JC, Pry RH (1970) A simple substitution model of tech nological change, Report 70 C 215. General Electric Company, R + D Centre Schenectaly NY. Technical Information Series
Frischknecht R (2001) Ecoinvent

Grabb M (1993) Energy policies and the greenhouse effect. The Royal Institute of International Affairs, Dartmouth

Gutschner M (2004) NET Nowak Energie \& Technologie AG, St. Urseren Switzerland (based on data from IEA)

Hug F, Bader H P, Scheidegger R, Baccini P (2004) A dynamic model to illustrate the development of an interregional energy household to a sustainable status. Clean Technol Environ Policy 6:138 148

IPCC (2000) Methodological and technological issues in technol ogy transfer, 2000th edn. ISBN 052180082

IPCC (2001) Climate change 2001. The scientific base UNEP

Müller D, Bader H P, Baccini P (2004) Physical characterization of regional long term timber management using a material and energy flow analysis. J Ind Ecol (in press)

Neumann T (2003) Deutsches Windenergie Institut, private com munications, unpublished

OECD/IEA (2004) World energy outlook 2004. International en ergy agency, Paris. http://www.oecvd.org

Real M (1998) A methodology for evaluating the metabolism in the large scale introductions of renewable energy systems. http://e collection.ethbib.ethz.ch/cgi bin/show.pl?type $=$ diss\&nr $=12937$

Schmid T, Bader H P, Scheidegger R, Lohm U (2004) The flow of phosphorus in food production and consumption linköping, Sweden, 1870 2000. J Resour Conserv Recycl (submitted)

UNDP (2000) World energy assessment: energy and the challenge of sustainability. United Nations Development Program II, New York

WEA (2000) World Energy Assessment, United Nations develop ment programme, energy and the challenge of sustainability. ISBN 9211261260 , September 2000

WEC (2000) Data from World Energy Assessment initiated by UNDP, UNDESA and World Energy Council in late 1998

Zeltner C, Bader H P, Scheidegger R, Baccini P (1999) Sustainable metal management exemplified by copper in the USA, Regional Environmental changes (1). Springer, Berlin Heidelberg New York, pp 3146 